\title{
O TRATAMENTO DA PRONÚNCIA EM COLEÇÕES DE ESPANHOL DO ENSINO MÉDIO APROVADAS PELO PNLD
}

\author{
José Ricardo Dordron de Pinho*
}

\begin{abstract}
RESUMO: Este trabalho analisa o tratamento dado à pronúncia pelas coleções de Espanhol do Ensino Médio aprovadas no PNLD 2018. Apesar de conteúdos de pronúncia não constituírem uma exigência do programa, é possível encontrá-los em duas das três coleções aprovadas, o que indica a percepção de seus autores da importância do assunto para o processo de ensino-aprendizagem de uma língua estrangeira. Como suporte teórico, o trabalho se baseia em Iruela (2007), para quem a oralidade não existe sem o suporte da pronúncia. Tomando como objeto de análise as propostas de cada coleção para o trabalho com a pronúncia e a efetiva abordagem do tema, percebemos que o trabalho com a pronúncia se encontra relacionado, quase exclusivamente, com a compreensão auditiva, ainda que se tratem tanto aspectos segmentais quanto prosódicos. Há poucas atividades práticas, principalmente quanto à produção.
\end{abstract}

PALAVRAS-CHAVE: Ensino da pronúncia; língua espanhola; PNLD.

\section{Introdução}

A pronúncia é um elemento de fundamental importância para a comunicação oral. No entanto, sua presença não é frequente nas aulas de Espanhol (nem nas de línguas estrangeiras em geral) da Educação Básica. Uma justificativa é o fato de raramente se desenvolverem habilidades orais nesse nível. Tal justificativa talvez pudesse ser aceitável, mas vale lembrar que a ausência de atividades de pronúncia pode ser percebida mesmo quando a oralidade se faz presente. Nesse caso, as justificativas costumam ser pouco conhecimento sobre o assunto por parte do professor e/ou não existência de recursos didáticos. De qualquer maneira, a situação de um trabalho com a pronúncia se torna ainda mais deficiente pelo fato de ela também não estar presente no edital do PNLD e de aparecer de forma muito limitada nos documentos oficiais.

\footnotetext{
* Doutor em Letras Neolatinas pela Universidade Federal do Rio de Janeiro (UFRJ). Professor do Colégio Pedro II.
} 
Apesar da total exclusão do tema "pronúncia" no edital do PNLD e sua presença quase despercebida nos documentos oficiais, o assunto é abordado em duas das três coleções de Espanhol aprovadas no PNLD 2018 (Ensino Médio). Tal fato ocorre, provavelmente, pela percepção de seus autores da importância da pronúncia para uma plena comunicação oral, incluindo tanto a compreensão quanto a expressão. Neste trabalho, então, pretendemos analisar como essas duas coleções tratam o assunto, considerando os temas específicos (segmentais e prosódicos) que são abordados e se estabelecem uma relação da pronúncia com as duas habilidades orais ou apenas com uma delas. Este estudo traz contribuições para a promoção do ensino de pronúncia, mas vai além, ao refletir sobre aspectos relacionados ao livro didático de línguas estrangeiras no Brasil.

O trabalho se estrutura da seguinte maneira: nesta primeira seção, introduzimos o tema a ser abordado. Na segunda seção, discutimos a relevância de se trabalhar pronúncia em aulas de línguas estrangeiras, bem como o que há (se é que há) sobre ela no PNLD e nos documentos oficiais. Em seguida, descrevemos os procedimentos de pesquisa. Na seção seguinte, apresentamos a análise da abordagem da pronúncia nas coleções de Espanhol aprovadas pelo PNLD 2018. Por fim, apresentamos as considerações finais.

\section{Pronúncia e comunicação}

Neste artigo, descrevemos e analisamos o trabalho com pronúncia em livros didáticos de Espanhol. Essa proposta se justifica pelo fato de a pronúncia ser fundamental para a comunicação oral e, dessa forma, trazer contribuições importantes para o desenvolvimento da oralidade nos alunos. Afinal, como afirma Iruela (2007, p. 3), entre diversos outros autores, a pronúncia é o suporte da transmissão da informação oral; isso significa que é o elemento condicionador da inteligibilidade da mensagem.

Apesar do que afirmamos anteriormente, é comum que a pronúncia seja excluída das aulas de línguas estrangeiras. Em geral, esse fato se deve a problemas na formação docente e à ausência de material disponível no mercado, mas os professores tendem a reconhecer seu valor. Cabe enfatizar que a pronúncia não deve ser estudada pelo simples fato de se buscar uma boa pronúncia, com um fim em si mesmo, mas sim como uma ferramenta que permitirá tornar a oralidade inteligível.

Problemas de pronúncia, sejam em nível segmental ou prosódico, podem levar a uma compreensão equivocada ou a uma não compreensão. O uso de um som no lugar de outro, de um som inexistente na língua ou de um padrão prosódico que caberia em determinado contexto na língua materna, mas não na língua objeto de estudo são exemplos de problemas 
que dificultam (ou mesmo impedem) a comunicação. Assim, ratificamos que a presença de atividades de pronúncia em aulas de línguas estrangeiras traz grande contribuição para o desenvolvimento da oralidade.

\section{O trabalho com a pronúncia}

Como visto anteriormente, é fundamental que se desenvolvam atividades de pronúncia se se espera que os estudantes desenvolvam sua competência comunicativa em nível oral. Nesse sentido, pretendemos discutir dois aspectos aqui: os dois níveis em que a pronúncia se subdivide e a ordem do trabalho com a pronúncia considerando as habilidades de compreensão e de expressão.

Considerando o primeiro item para discussão, a subdivisão das atividades de pronúncia, vale ressaltar que ela se apresenta em dois níveis: o segmental e o prosódico. No nível segmental, estudam-se os sons isoladamente, considerando-se suas características articulatórias; no nível prosódico, estudam-se os elementos que atuam sobre o enunciado como um todo (entoação, acento e ritmo). Faz-se necessário um trabalho com ambos os níveis, já que, entre as línguas objeto de estudo (neste caso, português e espanhol), apesar de haver elementos que possuem o mesmo valor, existem, também, sons e padrões prosódicos que apresentam valores linguísticos diferentes, além de sons e padrões prosódicos existentes em apenas uma das línguas. Tomemos como exemplo elementos segmentais: os sons [t] e $[\mathrm{t}]$ distinguem significado em espanhol, ou seja, exercem papel fonológico nessa língua, ao passo que, em português, correspondem a duas realizações alofônicas do fonema /t/. Consideremos, ainda, os sons fricativos $[\beta, \delta, \gamma]$ do espanhol, inexistentes em português.

Quanto ao segundo item desta seção, a ordem de trabalho com aspectos de pronúncia, cumpre destacar que, primeiramente, devem ser realizadas as atividades de compreensão, para, posteriormente, passar para as atividades de expressão. Tal sequência se justifica pelo fato de, para poder produzir um som ou um padrão prosódico, é necessário reconhecê-los previamente. Nesse sentido, destacamos a grande importância do trabalho com a pronúncia em atividades de compreensão: além de ser uma etapa prévia à de expressão, diversos estudos, listados em Nobre-Oliveira (2009), indicam a importância do treinamento perceptual, que leva a resultados positivos na expressão oral mesmo quando não se trabalha esta habilidade especificamente. 


\section{A pronúncia nos documentos oficiais}

O documento atualmente em vigor no Brasil, a BNCC (2017) ${ }^{1}$, traz apenas três referências à pronúncia. Num primeiro momento, fala-se de pronúncia quando se apresenta um dos eixos em que as propostas se dividem, o eixo "Oralidade". Nesse momento, a pronúncia é apresentada como um elemento importante para a comunicação, que constitui um suporte para ambas as habilidades orais; porém, não se apresenta nada mais detalhado.

Os outros dois momentos em que a BNCC fala de pronúncia ocorrem no detalhamento dos conteúdos: no $6^{\circ}$ ano, afirma-se que os estudantes devem " $[\mathrm{r}]$ econhecer semelhanças e diferenças na pronúncia de palavras da língua inglesa e da língua materna e/ou outras línguas conhecidas” (p. 251) e, no $7^{\circ}$ ano, “[r] econhecer a pronúncia de verbos regulares no passado (-ed)" (p. 255).

O que se percebe, ao considerar o tratamento da pronúncia pela BNCC, é que sua importância é reconhecida, mas não há um detalhamento de como abordar o tema, havendo, inclusive, uma minimização de sua prática, quando o documento propõe sua prática em apenas dois momentos, de forma muito limitada, sem uma associação a situações efetivamente comunicativas.

Apesar de termos tratado da BNCC, precisamos mencionar, sem dúvida, documentos anteriores, pelo fato de a BNCC ainda não estar em vigor na época de elaboração dos livros avaliados e aprovados pelo PNLD 2018. Dentre tais documentos, citamos as OCEM (2006), os PCN + (2002) e os PCN EM (1999). Se a BNCC trata a pronúncia de maneira absurdamente superficial, os documentos citados neste parágrafo conseguem ser ainda mais excludentes: o tema é sumariamente ignorado em todos eles. Dessa forma, causa-nos grande surpresa (de forma positiva) a presença de atividades de pronúncia em duas das coleções aprovadas, já que não havia qualquer sugestão nesse sentido nos documentos oficiais vigentes na época.

Antes da BNCC, comentários sobre pronúncia em documentos oficiais só podiam ser encontrados em material voltado para o nível anterior, os PCN do Ensino Fundamental (1998). Ainda que também não houvesse um grande aprofundamento, é o documento que mais tece comentários sobre esse assunto. Porém, a pronúncia aparece, quase sempre, relacionada apenas à expressão oral.

\footnotetext{
${ }^{1}$ A BNCC, diferentemente dos documentos oficiais anteriores, não conta com uma seção de Línguas Estrangeiras, mas de Inglês, especificamente. No entanto, tal conteúdo é apresentado como uma possibilidade de uso por outras línguas estrangeiras, se oferecidas pela escola.
} 
O documento afirma que o professor não precisa ser um especialista na área de fonética e fonologia, mas precisa conhecer alguns elementos que serão utilizados no processo de ensino-aprendizagem, e lista alguns deles. Dentre tais conhecimentos, faz-se referência tanto a aspectos segmentais quanto prosódicos. Por fim, na seção de orientações didáticas, os PCN EF destacam a importância de se estabelecer um nível aceitável de pronúncia para a comunicação e, ao incluir pela primeira (e única) vez comentários relativos também à compreensão auditiva, apresenta algumas atividades de pronúncia a serem desenvolvidas.

\section{A pronúncia no PNLD}

As coleções submetidas ao $\mathrm{PNLD}^{2}$ são avaliadas com base em um longo questionário. Tal questionário é dividido em blocos; o que nos interessa neste trabalho, da edição 2018, é o Bloco V, que aborda, de maneira conjunta, as habilidades de compreensão auditiva e de expressão oral.

Na edição do PNLD em análise, existe uma única pergunta que faz referência à pronúncia: trata-se da pergunta 52, que questiona se as coleções apresentam "atividades que permitem acesso, por meio da utilização do CD em áudio, a diferentes pronúncias, tanto dos sons individualmente, quanto do ponto de vista prosódico, em situações de compreensão oral”. Percebemos que o PNLD não reconhece a importância da pronúncia, limitando-a a uma pergunta que não valoriza a pronúncia propriamente dita, mas a relaciona à questão da variação linguística. A pergunta 52 aborda a pronúncia, mas apenas para contribuir para que os estudantes percebam que o espanhol - como todas as línguas - é passível de variação.

Além da questão anteriormente discutida, outro ponto problemático é que a pronúncia é relacionada apenas à habilidade de compreensão auditiva, não à de expressão oral. Pelo que discutimos nas seções anteriores, para um pleno desenvolvimento da oralidade, precisamos, primeiramente, reconhecer os sons e os padrões prosódicos da língua que estudamos e, depois, aprenderemos a reproduzi-los, considerando funções, características específicas e elementos afins. A pergunta 52, porém, traz um aspecto positivo: ele demonstra que a pronúncia não se limita aos sons individuais, mas inclui o elemento prosódico.

Apesar de o PNLD 2018 não exigir nenhum tratamento didático da pronúncia, elemento sem o qual não existe oralidade, ela é tratada em duas das três coleções aprovadas nessa edição. As formas de abordagem são bastante diversas, como veremos mais adiante. No entanto, a sua presença em ambas as coleções "sem necessidade" (por não serem

\footnotetext{
2 Ainda que os comentários aqui apresentados sirvam, basicamente, para as diversas edições do PNLD, referimo-nos especificamente à edição 2018.
} 
exigência do edital) indicam que seus autores reconhecem a grande relevância do tema para o desenvolvimento da escuta e da fala em espanhol.

\section{Metodologia}

Com o objetivo de avaliar as atividades voltadas para a prática da pronúncia, tomamos como objeto de análise as três coleções de Espanhol aprovadas na edição 2018 do PNLD de Ensino Médio: Cercanía joven (SM), Confluencia (Moderna) e Sentidos en lengua española (Richmond). Apresentamos, nesta seção de metodologia, o que cada manual do professor apresenta sobre pronúncia, bem como o espaço destinado às explicações e/ou atividades relativas a esse tema, além de listar os tópicos abordados pelas coleções.

\section{Os manuais do professor}

\section{Coleção Cercanía joven}

A coleção afirma possuir uma proposta com atividades que integrem as 4 habilidades: "Se espera que el alumno escuche y lea compreensivamente y que se exprese, tanto oralmente como por escrito, con propiedad y corrección” (p. 190). Trata especificamente da pronúncia tanto ao falar especificamente da compreensão auditiva quanto ao falar da expressão oral, ou seja, identifica-se uma associação da pronúncia às duas habilidades orais.

No primeiro caso, apresenta-se a importância do reconhecimento do som isolado, bem como de aspectos prosódicos, como entoação, ênfase e velocidade (p. 193). Aparentemente, a coleção dá grande importância aos elementos prosódicos, ao mencionar sua importância para a percepção de aspectos identitários e comunicantes: pode transmitir sentimentos, como alegria, falsidade e força, e características individuais, tanto "por medio del volumen y de la entonación de la voz, como mediante su timbre” (p. 193). Em síntese, a coleção afirma que, para os ouvintes entenderem o que é dito, "deben no solo moverse por entre los diferentes sonidos, los significados de las palabras y las estructuras gramaticales, sino también interpretar la entonación de la voz, el énfasis, la intención comunicativa” (p. 193), ou seja, é dado um grande destaque aos aspectos prosódicos.

Questões de pronúncia são retomadas na seção que trata da expressão oral. A coleção se baseia no que dizem Cassany, Luna e Sanz (1994, p. 151) e comentam que, "para ser un buen comunicador, el hablante debe saber agregar a su producción oral tanto la corrección y precisión léxica y gramatical como la fluidez, velocidad y ritmo en el habla. Además, debe intentar producir una pronunciación clara y segura para expresarse de un modo más coheso y coherente” (pp. 194-195). Apesar de, neste momento, a coleção não detalhar o trabalho 
com os níveis segmental e prosódico, segue demonstrando a importância da pronúncia para a comunicação oral.

\section{Coleção Confluencia}

No Manual do Professor, os comentários relativos à pronúncia se encontram na subseção "Expresión y comprensión oral”, especificamente na página 141. Ainda que tal subseção trate de maneira conjunta das duas habilidades orais, aparentemente a coleção relaciona o item pronúncia apenas à compreensão auditiva.

Apesar de comentar que apresenta estímulos à observação de aspectos específicos de pronúncia, "con la finalidad de despertar la conciencia de la relación de los(as) estudiantes con su pronunciación en la lengua española”, os comentários específicos remetem, em sua maioria, a aspectos prosódicos. Tal comentário se baseia, por exemplo, na afirmação de que o reconhecimento de certas características, tais como pausas inesperadas e uma elevação do tom de voz, "está al servicio (...) de una comprensión más plena”. A questão da pausa é retomada para tratar dos diversos significados que pode possuir, como ênfase ou censura.

Com relação a aspectos segmentais, o único comentário se refere à existência de exercícios de compreensão auditiva em que se trabalham atividades intensivas, quando o objetivo é "identificar inflexiones específicas, formas de pronunciar un determinado sonido, etc.)" aqui, apesar do comentário relativo ao nível segmental, observa-se, mais uma vez, uma associação com a prosódia. A partir do que o manual do professor apresenta, espera-se encontrar, no interior da coleção, uma ênfase da pronúncia voltada para aspectos prosódicos, em detrimento de aspectos segmentais, e que relacione questões de pronúncia apenas a uma das habilidades orais, a de compreensão auditiva.

\section{Coleção Sentidos en lengua española}

O manual de Sentidos en lengua española não faz qualquer referência à pronúncia, o que nos leva à conclusão de que o tema não será abordado ao longo da coleção. Ao apresentar os objetivos gerais da coleção (p. 166), um deles afirma que se espera "desenvolver práticas de linguagem em língua espanhola, tanto de compreensão quanto de produção, em situações concretas de interação"; no entanto, pouco depois (p. 173), é possível ler que “(...) a leitura é a competência que mais valorizamos nesta coleção, embora a proposta contemple a compreensão e a produção tanto de gêneros escritos quanto de gêneros orais" e que “(...) consideramos válidos também (...) os argumentos em favor do foco na leitura". A partir desses comentários, podemos inferir uma possível razão para a exclusão de atividades com pronúncia 
(além de não ser exigido pelo PNLD, naturalmente): mesmo que se trabalhe a oralidade, o foco não está nela.

\section{Os espaços destinados às atividades de pronúncia Coleção Cercanía joven}

A coleção, no material destinado aos alunos, se divide em 6 unidades, cada uma subdividida em 2 capítulos. Cada um desses capítulos trabalha, prioritariamente, duas habilidades linguísticas, de modo que todas as unidades trabalham com as 4 habilidades. As seções de expressão oral não possuem um momento voltado para a pronúncia, mas as de compreensão auditiva, sim; estas se subdividem em 4 subseções, voltadas, respectivamente, para a préescuta, a escuta, a pós-escuta e a pronúncia.

A subseção dedicada à pronúncia se intitula "Oído perspicaz: El español suena de maneras diferentes", que corresponde a uma etapa específica para "la pronunciación, la variación fonética y fonológica y la ortografía de la lengua española” (p. 200). Ao detalhar o foco da subseção, a coleção afirma que "es la pronunciación de determinadas letras del alfabeto español y el análisis contrastivo con la lengua portuguesa. Además, se trabajan algunas variedades" (p. 200). Ao considerarmos os dois comentários, vemos que a subseção dedicada às atividades de pronúncia tem 4 objetivos: (a) apresentar aos estudantes alguns sons do espanhol (nível segmental), (b) trabalhar com as dificuldades específicas do falante de PB ao aprender espanhol do ponto de vista da pronúncia, (c) apresentar questões de variação na pronúncia e $(\mathrm{d})$ relacionar a pronúncia à ortografia. Vale ressaltar que tais atividades, a partir da leitura do manual, se encontrarão relacionadas única e exclusivamente às atividades de compreensão, não de expressão.

\section{Coleção Confluencia}

Pelo que foi observado nos comentários do Manual do Professor, a pronúncia será efetivamente considerada; porém, não existe uma seção específica destinada a essa função. O que se espera a partir da leitura do manual é que as questões relativas à pronúncia estejam desenvolvidas dentro das atividades de compreensão auditiva (assim como na coleção anterior, aparentemente, a pronúncia se relacionará exclusivamente à habilidade de compreensão oral). 


\section{Coleção Sentidos en lengua española}

A partir do momento em que a coleção não desenvolve atividades de pronúncia, ela não conta, obviamente, com uma seção destinada a esse fim.

\section{Os conteúdos de pronúncia abordados pelas coleções}

Os quadros 1 e 2 apresentam os conteúdos de pronúncia abordados, respectivamente, nas coleções Cercanía joven e Confluencia. Não serão apresentadas mais referências à coleção Sentidos en lengua española a partir deste momento no trabalho, pelo fato de não haver nenhuma atividade de pronúncia nessa coleção. Comecemos por Cercanía joven.

Quadro 1 - Conteúdos de pronúncia abordados na coleção Cercanía joven. Os espaços com --- indicam que não há conteúdos de pronúncia (o referido capítulo não conta com uma seção de compre-

\begin{tabular}{|c|c|c|c|}
\hline & $1^{a}$ & $2^{\mathrm{a}}$ & $3^{\mathbf{a}}$ \\
\hline $\begin{array}{l}\text { Unidade } 1 \text { - } \\
\text { Capítulo } 1\end{array}$ & Alfabeto - $\tilde{N}$ & --- & $\mathrm{V} / \mathrm{B}$ \\
\hline $\begin{array}{l}\text { Unidade } 1 \text { - } \\
\text { Capítulo } 2\end{array}$ & --- & $\mathrm{D}, \mathrm{T}, \mathrm{CH}$ & --- \\
\hline $\begin{array}{l}\text { Unidade 2- } \\
\text { Capítulo } 3\end{array}$ & --- & --- & consoantes nasais \\
\hline $\begin{array}{l}\text { Unidade } 2 \text { - } \\
\text { Capítulo } 4\end{array}$ & $\mathrm{LL} / \mathrm{Y}$ & $\begin{array}{c}\text { R-, -R-, -R } \\
\text { RR }\end{array}$ & --- \\
\hline $\begin{array}{l}\text { Unidade 3- } \\
\text { Capítulo } 5\end{array}$ & --- & --- & --- \\
\hline $\begin{array}{l}\text { Unidade 3- } \\
\text { Capítulo } 6\end{array}$ & $\mathrm{Z}, \mathrm{S}, \mathrm{C}+\mathrm{E} / \mathrm{I}$ & $\mathrm{G} / \mathrm{J}$ & sons do X \\
\hline
\end{tabular}

Fonte: a própria coleção.

Como visto no quadro 1 , a seção destinada à pronúncia na coleção Cercanía joven trata apenas de aspectos segmentais, o que já era esperado, pois, como vimos na seção 3.2, o manual do professor da referida coleção traz como objetivo trabalhar “(...) la pronunciación de determinadas letras del alfabeto español (,,)”. Porém, alguns aspectos prosódicos são abordados na seção "Chuleta lingüística: jno te van a pillar!", que vem ao final de cada volume. No volume 1, a coleção trata dos sinais de pontuação e de suas funções; no volume 2, da acentuação; e, no volume 3, de entoação.

Passemos, agora, a Confluencia. 
Quadro 2 - Conteúdos de pronúncia abordados na coleção Confluencia -

\begin{tabular}{|c|c|c|c|}
\hline & $1^{a}$ & $2^{a}$ & $3^{a}$ \\
\hline Exercícios & $\begin{array}{c}\text { * entoação - funções } \\
\text { (un. 4) }\end{array}$ & $\begin{array}{l}\text { * substituição de [r] } \\
\text { por [1], perda ou aspi- } \\
\text { ração do } \\
\text { “-s" final, aspiração, } \\
\text { perda do "-d" final, } \\
\text { acento neutro, ausên- } \\
\text { cia de seseo (un. 4) }\end{array}$ & $\begin{array}{c}\text { * pronúncia segmental } \\
\text { e entoação - reflexões } \\
\text { sobre as dificuldades } \\
\text { (un. 1) }\end{array}$ \\
\hline $\begin{array}{l}\text { Seção "Comentario } \\
\text { lingüístico" }\end{array}$ & $\begin{array}{c}\text { * acentuação gráfica } \\
\text { (classificação e regras } \\
\text { gerais) }\end{array}$ & $\begin{array}{l}\text { * acentuação gráfica } \\
\text { - acento diacrítico } \\
\text { (un. } 1 \text { ) } \\
* \text { seseo (un. } 3 \text { e } 4 \text { ) }\end{array}$ & \\
\hline
\end{tabular}

Fonte: a própria coleção.

A coleção Confluencia não possui uma seção destinada exclusivamente à pronúncia; os conteúdos relativos a esse item, de maneira geral, são trabalhados dentro dos exercícios de compreensão auditiva. Eventualmente, porém, também são mencionados na seção "Comentario lingüístico", ao final de cada unidade (4 vezes em toda a coleção, sendo duas para tratar de acentuação ortográfica e duas relacionadas ao seseo).

Na próxima seção, discutiremos os itens aqui tratados: o que cada coleção afirma que fará, o que faz efetivamente (e como o faz) e que itens aborda, considerando os conteúdos segmentais e os prosódicos.

\section{Descrição e análise dos dados}

Considerando o objetivo deste trabalho, de avaliar as atividades de pronúncia nas coleções de Espanhol aprovadas na edição 2018 do PNLD de Ensino Médio, seguiremos, para a análise, a mesma ordem adotada na metodologia: o que diz o manual do professor, o espaço destinado às explicações e/ou atividades de pronúncia e os tópicos abordados pela coleção. Vale recordar que, como uma das coleções aprovadas, Sentidos en lengua española, não trata de questões de pronúncia, não a levaremos em consideração aqui.

\section{Os manuais do professor}

Pelos comentários apresentados no Manual do Professor na coleção Cercanía joven, é possível deduzir que a coleção atribui grande importância à pronúncia para a comunicação, ao relacioná-la tanto à compreensão quanto à produção. Diante dos comentários realizados, o que se espera é um trabalho com tal voltado para a prática da pronúncia em ambas as habilidades, o que, na prática, não ocorre - questões de pronúncia, ao longo da coleção, são encontradas apenas relacionadas à compreensão. Além disso, o manual destacou a 
importância tanto de aspectos segmentais quanto de aspectos prosódicos, mas, na coleção, apenas questões segmentais são abordadas nas unidades. Existem comentários relativos a questões prosódicas, mas limitadas a seções específicas.

Já com relação à coleção Confluencia, parece que a mesma vai num caminho oposto ao da coleção anterior: a ênfase está um pouco mais voltada para aspectos prosódicos, mas nenhum nível recebe grande atenção na coleção. Além disso, apesar de também trabalhar pronúncia apenas na compreensão e não na expressão, esse fato já estava indicado no manual.

\section{Os espaços destinados às atividades de pronúncia}

Como já visto, as duas coleções limitam o trabalho com pronúncia à habilidade de compreensão oral, sem relacioná-la à expressão oral, salvo em algumas raras ocasiões, mas, mesmo assim, dentro da seção de compreensão oral.

As duas coleções tratam a pronúncia de forma bastante diferenciada: ao passo que a coleção Cercanía joven opta por um ensino explícito de pronúncia, com uma seção destinada para tal fim, que inclui explicações teóricas, a coleção Confluencia dá preferência a um ensino um pouco mais implícito, com questões de reflexão dentro das atividades de compreensão auditiva. Pode-se até mesmo afirmar que esta última coleção não ensina pronúncia, mas sim reflete sobre ela, limitando-se a casos de variação. É possível observar, ainda, outro aspecto que distingue as coleções: ao passo que Cercanía joven prioriza questões segmentais, Confluencia, ainda que por uma pequena diferença, prioriza o nível prosódico.

\section{Os conteúdos de pronúncia abordados pelas coleções}

Como acabamos de ver, Cercanía joven dá mais ênfase ao trabalho com conteúdos segmentais e Conflencia, dá certa prioridade a questões prosódicas. Nesta seção, analisaremos como os conteúdos são abordados, sejam segmentais ou prosódicos.

\section{Os conteúdos de pronúncia}

Trataremos, primeiramente, dos conteúdos de prosódia e passaremos, em seguida, para os de nível segmental.

\section{Os conteúdos de pronúncia em nível prosódico}

Os conteúdos de prosódia não são tratados de forma sistemática pela coleção Cercanía joven, que não os aborda em sua seção de pronúncia, inserida nas unidades, para abordagem 
específica do tópico "pronúncia". Nessa coleção, questões prosódicas são apresentadas apenas em uma seção que aparece ao final de toda a coleção, com um conteúdo abordado em cada volume (existe apenas um único momento em que uma questão prosódica é tratada dentro da coleção, mas antes da parte específica de pronúncia).

$\mathrm{Na}$ coleção Confluencia, tampouco se observa uma sistematização para o tratamento de temas prosódicos. Como já mencionado, essa coleção inclui questões de pronúncia em atividades, sem uma explicação teórica. Questões relacionadas à entoação são abordadas em exercícios uma vez nos volumes 1 e 3; nos volumes 1 e 2, trata-se de questões de acento, com vistas à ortografia, uma vez em cada um desses volumes, na seção "Comentario lingüístico", que aparece ao final das unidades. Trata-se de um momento de formalização de conteúdo. No volume 2, aborda-se uma vez a prosódia de maneira ampla.

\section{Os conteúdos selecionados para o nível prosódico}

A coleção Cercanía joven aborda apenas um conteúdo prosódico em cada volume, na seção intitulada “Chuleta lingüística: jno te van a pillar!”, que vem ao final do livro e que tem a função de apresentar tabelas de conteúdos gramaticais, com regras de forma e de uso. Os temas tratados pela coleção são sinais de pontuação e suas funções (volume 1), acentuação (volume 2) e entoação (volume 3). No volume 3, há uma breve atividade, dentro da seção de compreensão auditiva, relativa à entoação.

A coleção Confluencia aborda um conteúdo de entoação nos volumes 1 e 3 , um conteúdo de acento nos volumes 1 e 2 e um conteúdo geral de prosódia no volume 2. Quanto à entoação, trata-se de suas funções e das dificuldades relativas a esse aspecto ao se aprender uma língua estrangeira. Com relação ao acento, trata-se da acentuação com vistas à escrita. $\mathrm{E}$ sobre a prosódia, considera-se a questão do acento neutro.

\section{Análise das atividades para o nível prosódico}

A coleção Cercanía joven se limita a abordar os aspectos prosódicos apenas com explicações teóricas e exercícios escritos, sem nenhuma prática oral, seja de compreensão ou de expressão. Vale recordar que tais temas são tratados apenas ao final da coleção, no interior de uma seção cujo objetivo é formalizar conteúdos. Assim, os três conteúdos prosódicos tratados em toda a coleção (sinais de pontuação e suas funções, acentuação e entoação) têm sua atenção totalmente voltada para questões de ortografia.

O volume 1, ao tratar dos sinais de pontuação, apresenta uma lista com seus nomes e dois exercícios: (1) relacionar o nome e a forma à função e (2) pontuar um texto. O volume 
2, que trata da acentuação, explica que todas as palavras possuem uma sílaba tônica - nos exercícios, a coleção se limita a 6 grupos de pares de palavras, para que se identifique a que está acentuada de forma incorreta, mas sem apresentar as regras. Por fim, o volume 3 trata da entoação ao telefone, em que, como é dito, é possível usar expressões com entoação interrogativa e é importante usar uma "entoação amável" - esse é o único comentário, com o exercício solicitando apenas que um diálogo seja completado com certas expressões.

O único caso de um aspecto prosódico abordado no interior da coleção se encontra no último capítulo do volume 3 , inserido em um exercício da seção de compreensão auditiva. Nessa atividade, é explicado aos estudantes que, no áudio em questão, é possível notar diversas emoções na fala das personagens e, em seguida, é dada uma lista com várias delas. Ao ouvir o áudio novamente, acompanhado de sua transcrição, a atividade solicita que se escreva, nos espaços correspondentes, a emoção presente nesse momento.

A abordagem que a coleção Confluencia dá aos elementos prosódicos possui duas faces: em exercícios, inseridos nas atividades de compreensão auditiva, e numa seção que tem por finalidade formalizar conteúdos linguísticos.

No primeiro caso, os exercícios estão relacionados às funções da entoação (volume 1), ao acento neutro (volume 2) e às dificuldades de pronúncia no processo de aprendizagem de uma língua estrangeira (volume 3).

No tocante a questões de prosódia inseridas nos exercícios, não se observa um ensino propriamente dito de seus elementos, mas uma reflexão que não deixa de corresponder a um ensino implícito, mas que talvez, na prática, não seja muito produtivo, pois ocorre de maneira isolada, com poucas questões e sem uma prática oral - seja de compreensão ou de expressão.

No volume 1, ao se tratar das funções da entoação, explica-se o efeito que ela pode produzir e, a partir da audição de uma frase do texto, os estudantes devem marcar possíveis interpretações resultantes da entoação utilizada. No volume 2 , não se ouve nem se produz nada especificamente para o trabalho com a prosódia, sendo uma atividade totalmente reflexiva: a atividade se limita a discutir a inexistência do acento neutro. Por fim, no volume 3, o exercício, relacionado a uma atividade de compreensão auditiva, leva a uma percepção de dificuldades pessoais ao se falar uma língua estrangeira, tanto em nível prosódico quanto segmental. Os estudantes devem identificar em que aspectos apresentam maior dificuldade e como superá-los. Esta última atividade parece um pouco incoerente com as atividades desenvolvidas ao longo da coleção: os estudantes devem pensar em como superar dificuldades de pronúncia, mas em nenhum momento foram apresentadas a eles atividades que propusessem algo voltado para esse fim. 
Com relação à seção em que se formalizam conteúdos linguísticos, o acento é tratado em dois momentos: no volume 1, apresentam-se as regras gerais e, no volume 2 , apresentamse as regras dos casos diacríticos. Nesses dois casos, o conteúdo é totalmente voltado para questões ortográficas, sem nenhuma preocupação com questões de pronúncia. Porém, cabe ressaltar que, após as explicações e os exemplos, não são propostos exercícios nem mesmo voltados para a ortografia.

\section{Os conteúdos de pronúncia em nível segmental}

Em questões relacionadas ao nível segmental, as coleções se opõem mais uma vez: é o aspecto que predomina na coleção Cercanía joven, ao passo que é um conteúdo pouco presente na coleção Confluencia.

\section{Os conteúdos selecionados para o nível segmental}

Os elementos segmentais abordados pela coleção Cercanía joven se encontram todos na seção de compreensão auditiva, o que os exclui, pelo menos a princípio, de uma prática para a expressão oral. Os temas abordados são poucos, num total de 3 itens por volume: alfabeto e letra Nं; LL/Y; Z, S, C + E/I (volume 1), D, T, CH; R-, -R-, -R, RR; G/J (volume 2), V/B; consoantes nasais; sons do X (volume 3). Pela listagem dos conteúdos, fica evidente que a abordagem parte da ortografia para tratar os sons representados pelas letras em questão.

A coleção Confluencia, da mesma forma do que ocorre com aspectos prosódicos, dá pouca importância a aspectos segmentais. Trabalha apenas com fenômenos de variação: seseo, lambdacismo, aspiração e perda do $\_$d final, além de tratar dificuldades durante a aprendizagem de uma língua estrangeira.

\section{Análise das atividades para o nível segmental}

A coleção Cercanía joven apresenta, no total, nove seções voltadas para questões de pronúncia segmental. Em todas elas, repetem-se dois aspectos importantes para a percepção dos sons trabalhados: parte-se de uma audição de palavras com o(s) som(ns) a ser(em) trabalhado(s) e se fazem perguntas reflexivas para que os alunos percebam (e expliquem) questões relacionadas à pronúncia do espanhol e a dúvidas que brasileiros podem ter.

Com relação a ouvir um áudio para se desenvolver a atividade, esse é um elemento fundamental, que precisa estar presente. Não se perceberá um som apenas com explicações 
teóricas; é preciso ouvi-lo para, efetivamente, percebê-lo. Torna-se importante, também, destacar que, das 9 seções, 8 retomam palavras do áudio original.

Quanto à reflexão apresentada nas atividades, temos outro item importante para a percepção dos sons. Ao fazer com que os estudantes tenham de perceber a realização e suas possíveis dificuldades para descrevê-las e explicá-las, a internalização do conteúdo terá mais chances de ocorrer de maneira efetiva. Os estudantes, para essa prática, são guiados por meio de algumas perguntas que os levam à percepção do ponto ao qual devem se atentar.

Além dos aspectos apresentados, seria importante que se seguisse o momento da prática. Como o objetivo é a oralidade, seria conveniente encontrar atividades voltadas para a prática da compreensão e da expressão, além da escrita. Num primeiro momento, atividades de expressão estariam ausentes, pelo fato de as atividades estarem em uma seção de compreensão. $\mathrm{Na}$ prática, porém, aparecem atividades voltadas para os três aspectos: compreensão, expressão e escrita. Lamentavelmente, em sua maioria, as atividades envolvem apenas questões de ortografia, mesmo estando presentes em uma seção de pronúncia.

Das 9 seções de pronúncia, após a audição e as questões reflexivas, 8 apresentam exercícios. Desses exercícios, apenas duas seções estão voltadas para a expressão, ainda que de maneira muito limitada: soletrar palavras e, em outra unidade, ler uma lista. Das 6 seções restantes, percebe-se que 4 estão totalmente voltadas para questões de ortografia; 1 possui exercícios de escuta; e 1 possui exercícios de escuta e de ortografia. Em síntese, a coleção Cercanía joven, em sua seção de pronúncia, tem o grande mérito de levar os estudantes a ouvirem especificamente os sons a serem trabalhados e de levá-los a uma reflexão sobre os mesmos, mas peca no momento de praticá-los, pois tal prática, voltada para a oralidade, é mínima, com a ênfase voltada para aspectos ortográficos.

Quanto à coleção Confluencia, são encontradas duas abordagens para aspectos segmentais, cada uma ocorrendo apenas duas vezes, dada a escassez de um trabalho voltado para tais aspectos. Uma das abordagens se dá nos próprios exercícios; porém, mais do que um processo de ensino de aspectos de pronúncia, o que se observa, de fato, é uma reflexão voltada para a questão da variação linguística.

$\mathrm{Na}$ primeira vez em que se trabalha com pronúncia segmental em Confluencia un. 4, vol. 2), encontram-se 4 questões. As três primeiras solicitam que os estudantes copiem, da leitura de um texto escrito que foi acompanhada pelo áudio, exemplos de lambdacismo, aspiração e perda de -s; em todos os casos, faz-se, anteriormente, uma breve explicação do fenômeno. A última questão solicita a identificação, sem qualquer explicação prévia, de outros casos em que se verifique variação de pronúncia (o gabarito traz a perda do $-\mathrm{d}$ final). $\mathrm{O}$ 
único outro momento em que se trabalham questões de pronúncia é na unidade 1 do volume 3, mas também apenas para reflexão: os estudantes devem pensar nas principais dificuldades de pronúncia que os brasileiros têm ao aprender espanhol. O grande problema é que tal aprendizagem teve de ser intuitiva, pois a coleção não se deteve no assunto.

Além dos casos mencionados anteriormente, a pronúncia é mencionada duas vezes na seção Comentario lingüistico (un. 3 e 4, vol. 2), ainda que ambas tratem do mesmo assunto, o seseo. As explicações, totalmente teóricas, descrevem o fenômeno, comentam um áudio ouvido anteriormente e o relacionam a espaços geográficos. Prática oral, seja de produção ou mesmo apenas de percepção, não há nenhuma.

\section{Comentários finais}

Considerando as análises realizadas, percebe-se a inclusão do tema pronúncia em duas das três coleções de Espanhol aprovadas no edital 2018 do PNLD, dos Ensino Médio, a despeito de sua não obrigatoriedade, se considerado o referido edital. Uma das coleções, Cercania joven, chega a trabalhar o assunto de forma prática, ainda que de uma maneira bastante tímida. Já a coleção Confluencia se limita a uma reflexão sobre a questão da variação linguística. Apesar desses problemas, consideramos válida a inclusão do tema nas coleções, uma vez que se trata de um conteúdo fundamental para uma efetiva prática oral.

Gostaríamos de pontuar alguns aspectos que poderiam ser revistos para o trabalho com a pronúncia. Cremos que a exclusão do Espanhol do PNLD impedirá um desenvolvimento do mesmo, pelo menos momentaneamente, mas não podemos deixar de tecer algumas sugestões aqui, algumas das quais já são realizadas pela coleção Cercanía joven.

Em primeiro lugar, as atividades devem partir do áudio - não se limitar a atividades escritas é fundamental. As explicações teóricas são importantíssimas, mas oferecer um caminho para que os próprios estudantes vão refletindo sobre as questões ajuda na percepção. Quanto à prática, se não houver, dificilmente os conteúdos serão plenamente internalizados; além disso, a prática não pode se limitar a questões ortográficas, ainda que elas precisem estar presentes. Sugerem-se exercícios primeiro de percepção e depois de produção, que vão de um trabalho mais controlado a uma prática oral totalmente livre, em que o professor esteja atento às dificuldades de seus alunos e que, após a conclusão das atividades, comente os problemas e/ou desenvolva atividades destacando os pontos ainda necessários.

\section{EL TRATAMIENTO DE LA PRONUNCIA EN COLECCIONES DE ESPAÑOL DE LA ENSEÑANZA MEDIO APROBADAS POR EL PNLD}

RESUMEN: Este trabajo analiza el tratamiento dado a la pronuncia por las colecciones de Español de la Enseñanza Media que aprobaron el PNLD 2018. A pesar de que contenidos de pronuncia no constituyan una 
exigencia del programa, es posible encontrarlos en dos de las tres colecciones aprobadas, lo que indica la percepción de sus autores de la importancia del asunto para el proceso de enseñanza-aprendizaje de una lengua extranjera. Como soporte teórico, el trabajo se basa en Iruela (2007), para quien la oralidad no existe sin el soporte de la pronuncia. Tomando como objeto de análisis las propuestas de cada colección para el trabajo con la pronuncia y el efectivo abordaje del tema, identificamos que el trabajo con la pronuncia se encuentra relacionado, casi exclusivamente, con la comprensión auditiva, aunque se traten tanto aspectos segmentales como prosódicos. Hay pocas actividades prácticas, principalmente en cuanto a la producción.

PALABRAS CLAVE: Enseñanza de la pronuncia; lengua española; PNLD.

\section{REFERÊNCIAS}

BRASIL. Ministério da Educação. PNLD 2018: espanhol - guia de livros didáticos - Ensino Médio. Brasília, DF: Ministério da Educação, Secretaria de Educação Básica, 2017.

BRASIL. Base Nacional Comum Curricular. Brasília: Ministério da Educação, 2017. Disponible en http://basenacionalcomum.mec.gov.br/documentos/bncc-2 v e r s a o . r evista.pdf. Acesso em 20-11-2020.

Orientações curriculares para o ensino médio. Linguagens, códigos e suas tecnologias. Brasília: Ministério da Educação, Secretaria de Educação Básica, 2006.

PCN+ Ensino Médio: Orientações Educacionais complementares aos Parâmetros Curriculares Nacionais. Linguagens, códigos e suas tecnologias./Secretaria de Educação Média e Tecnológica. Brasília: MEC; SEMTEC, 2002.

Ministério da Educação, Secretaria de Educação Média e Tecnológica. Parâmetros curriculares nacionais: ensino médio./Ministério da Educação. Secretaria de Educação Média e Tecnológica. Brasília: Ministério da Educação, 1999.

Secretaria de Educação Fundamental. Parâmetros curriculares nacionais: terceiro e quarto ciclo do ensino fundamental: língua estrangeira/Secretaria de Educação Fundamental. - Brasília: MEC/SEF, 1998.

COIMBRA, Ludmila \& CHAVES, Luíza Santana. Cercanía joven. São Paulo: Edições SM, 2016.

FREITAS, Luciana Maria de \& COSTA, Elzimar Goettenauer de Marins. Sentidos en lengua española. São Paulo: Richmond, 2016.

IRUELA GUERRERO, Agustín. ¿Qué es la pronunciación? In: redELE Revista Electrónica de Didáctica del Español como Lengua Extranjera. Febrero 2007, n. 9. Disponível em www.mecd.gob.es/redele/revistaRedEle/2007/primera.html. Acesso em 25/06/20.

NOBRE-OLIVEIRA, Denize. Efeitos do treinamento perceptual no aprendizado de sons de uma língua estrangeira: uma nova perspectiva. In: Anais do $3{ }^{\circ}$ CELLI. Colóquio de Estudos Linguísticos e Literários. Maringá: UEM-PLE, 2009. Disponível em ple.uem.br/3celli_anais/ficha.htm. Acesso em 15/09/20.

PINHEIRO-CORREA, Paulo \& LAGARES, Xoán Carlos. Confluencia. São Paulo: Moderna, 2016.

Recebido em: 28/12/2020.

Aprovado em: 06/04/2021. 